\title{
Chemical Vapor Synthesis of Size-Selected Zinc Oxide Nanoparticles
}

\author{
Sebastian Polarz, Abhijit Roy, Michael Merz, Simon Halm, Detlef Schröder, \\ Lars Schneider, Gerd Bacher, Frank E. Kruis, and Matthias Driess*
}

\begin{abstract}
$Z_{n O}$ can be regarded as one of the most important metal oxide semiconductors for future applications. Similar to silicon in microelectronics, it is not only important to obtain nanoscale building blocks of $\mathrm{ZnO}$, but also extraordinary purity has to be ensured. A new gas-phase approach to obtain size-selected, nanocrystalline $\mathrm{ZnO}$ particles is presented. The tetrameric alkyl-alkoxy zinc compound $\left[\mathrm{CH}_{3} \mathrm{ZnOCH}\left(\mathrm{CH}_{3}\right)_{2}\right]_{4}$ is chemically transformed into $\mathrm{ZnO}$, and the mechanism of gas-phase transformation is studied in detail. Furthermore, the morphological genesis of particles via gas-phase sintering is investigated, and for the first time a detailed model of the gas-phase sintering processes of $\mathrm{ZnO}$ is presented. Various analytical techniques (powder XRD, TEM/energy-dispersive X-ray spectroscopy, magic-angle spinning NMR spectroscopy, FTIR spectroscopy, etc.) are used to investigate the structure and purity of the samples. In particular, the defect structure of the $\mathrm{ZnO}$ was studied by photoluminescence spectroscopy.
\end{abstract}

\author{
Keywords: \\ - gas-phase reactions \\ - nanocrystalline materials \\ - semiconductors \\ - single-source precursors \\ - zinc oxide
}

\section{Introduction}

Nanostructures, that is, structures with at least one dimension less than $100 \mathrm{~nm}$, have received steadily growing interest as a result of their fascinating properties. ${ }^{[1-6]}$ There are two main reasons for alterations in properties: increased interface area, and the dominance of quantum size effects. An understanding of the effects due to miniaturization, their influence on the properties of materials, and the ex-

[*] Dr. S. Polarz, Dr. M. Merz, Dr. D. Schröder, Prof. M. Driess Institute of Chemistry, Technical University Berlin

Strasse des 17. Juni 135, 10623 Berlin (Germany)

Fax: (+49) 30-314-22168

E-mail: matthias.driess@tu-berlin.de

Dr. A. Roy, F. E. Kruis

Process and Aerosol Measurement Technology

Department of Electrical Engineering and Information Technology University Duisburg-Essen, 47057 Duisburg (Germany)

S. Halm, L. Schneider, Prof. G. Bacher

Department of Electrical Engineering and Information Technology University Duisburg-Essen

Bismarckstrasse 81, 47057 Duisburg (Germany) ploitation of these effects for the design of structures, devices, and systems with novel properties and functions are the major goals of contemporary nanoscience and nanotechnology. Besides metallic quantum dots, nanoparticles of transition-metal oxides are of high interest because variations in the morphology (size and shape), composition, and valence state of metals, as well as defect structures in the oxygen lattice, allow one to tune the electrical, optical, magnetic, mechanical, and last but not least, the chemical properties.

Among different wide-bandgap semiconductors, zinc oxide $(\mathrm{ZnO})$ is a key engineering material on it own merits. $\mathrm{ZnO}$ is a direct-bandgap semiconductor $\left(E_{\mathrm{g}}=3.37 \mathrm{eV}\right.$ at low temperature; $3.30 \mathrm{eV}$ at room temperature) with a free exciton binding energy of $60 \mathrm{meV}$, which ensures exciton emission at room temperature and above. This makes $\mathrm{ZnO}$ an excellent material for UV-light-emitting diodes (LEDs) and lasers. ${ }^{[7-9]} \mathrm{ZnO}$ is also used in solar cells, ${ }^{[10-12]}$ field-emission displays, highly efficient green phosphor ${ }^{[13]}$ UV photodetectors, ${ }^{[14]}$ gas sensors, ${ }^{[15]}$ varistors, ${ }^{[16]}$ and catalysts. ${ }^{[17]}$

It is envisaged that enhancement of properties would occur on decreasing the particle size into the nanometer 
range, so a great deal of effort has been made to synthesize nanostructured $\mathrm{ZnO}$ and to understand the resulting properties (see one of the recent reviews).$^{[18,19]}$ Thus, enormous efforts have been undertaken to gain control over the morphology and chemical features of $\mathrm{ZnO}$ nanoparticles by various techniques, for example, colloidal methods. ${ }^{[2-24]} \mathrm{Al}-$ though colloidal routes offer some control of particle size, the presence of unwanted chemical species on the particle surface influences the resulting properties. This is of great concern for practical use. Attempts have been made to remove the reactants and reaction products by washing. ${ }^{[2]}$ The question about the purity of the particles still remains, as some adsorbed species are strongly attached to the surface. ${ }^{[25]}$ Some adsorbed species can be removed by thermal treatment; however, this leads to agglomeration as well as reaction of the adsorbed species with the surface of the nanoparticles. ${ }^{[25]}$ This problem could hinder insights into the intrinsic properties of $\mathrm{ZnO}$ nanoparticles. Moreover, it seems rather difficult to derive samples with a particular particle size.

In this respect, gas-phase synthesis routes possess several advantages which could provide better control over particle morphology and crystallinity, and in addition allow continuous processing. ${ }^{[2]}$ However, true gas-phase routes have seldom been reported, and are even less studied in detail and understood. The flame pyrolysis of solutions containing $\mathrm{ZnO}$ precursors was performed by different groups, ${ }^{[27]}$ but neither the absence of impurities (from the solvent) nor a homogeneous distribution of particle morphology (size and shape) could be achieved. The evaporation and oxidation of elemental zinc at elevated temperature is the method of choice for the industrial production of $\mathrm{ZnO}$. This method leads to inhomogeneous particle morphologies as well, ${ }^{[15,28]}$ and details about processes during the gas-phase synthesis of metal oxide nanoparticles are still scarce.

In spite of huge activity toward the synthesis of nanostructured $\mathrm{ZnO}$, a simple method for the formation of impurity-free $\mathrm{ZnO}$ nanoparticles with controlled morphology remains an important challenge. The present work is devoted to the gas-phase synthesis of pure, poly- and monodisperse nanocrystalline $\mathrm{ZnO}$ particles by chemical means (chemical vapor synthesis, CVS) using a volatile organometallic $\mathrm{ZnO}$ precursor. CVS is performed at higher process temperatures, higher precursor partial pressure, and longer residence time than chemical vapor deposition (CVD), thus resulting in particle formation. ${ }^{[29,30]}$ The clear advantage of using molecular organometallic precursors in the CVS process over ionic precursors is that the former have a significantly higher vapor pressure and lower decomposition temperatures, which enable the formation of initially very small particles. Several organometallic precursors are reported in the literature for metal-organic chemical vapor deposition (MOCVD) of $\mathrm{ZnO}$ thin films. ${ }^{[31]}$ In this context, the formation of $\mathrm{ZnO}$ nanoparticles from dimethylzinc reported by Roth et al. deserves attention. ${ }^{[32]}$ They prepared $\mathrm{ZnO}$ from $\mathrm{Zn}\left(\mathrm{CH}_{3}\right)_{2}$ in a low-pressure $\mathrm{H}_{2} / \mathrm{O}_{2} / \mathrm{Ar}$ flame reactor as well as in an $\mathrm{Ar} / \mathrm{O}_{2}$ microwave plasma reactor, and investigated the particle formation process in situ by particle mass spectrometry. However, no detailed investigation has been per- formed on the size-classified nanoparticles. ${ }^{[32]}$ The use of dimethylzinc as a precursor for zinc oxide has some inherent disadvantages: dimethylzinc is a very reactive compound toward oxygen and moisture which spontaneously burns in air. This makes it not only difficult to handle, but also difficult to perform reactions in a controlled manner.

Here, we report a detailed investigation of the CVS of $\mathrm{ZnO}$ nanoparticles using the volatile organometallic precursor $\left[\mathrm{CH}_{3} \mathrm{ZnOCH}\left(\mathrm{CH}_{3}\right)_{2}\right]_{4}$ (subsequently denoted "heterocubane"). This precursor has the advantages that it is easily accessible, even on the multigram scale, and can be handled in air. It is interesting to note that a similar precursor containing ethylzinc groups instead of methylzinc was recently used to prepare $\mathrm{ZnO}$ particles by a colloidal method using surfactant. ${ }^{[33]}$ In this paper, we explore the fundamental differences between the solid-state versus the gas-phase chemistry of the precursor $\left[\mathrm{CH}_{3} \mathrm{ZnOCH}\left(\mathrm{CH}_{3}\right)_{2}\right]_{4}$. This allows for the first time the detailed investigation of the formation of $\mathrm{ZnO}$ agglomerates in the gas phase from a chemical point of view. In addition, their in-flight sintering was studied quantitatively. Thus, $\mathrm{ZnO}$ particles with controlled morphology, high crystallinity, and high purity have been obtained. Furthermore, the physical properties of the resulting $\mathrm{ZnO}$ particles are studied by various spectroscopic techniques. In particular, the photoluminescence (PL) properties and related defect structures of $\mathrm{ZnO}$ are reported.

\section{Results and Discussion}

To obtain $\mathrm{ZnO}$ materials of high purity, the following requirements have to be fulfilled for a good precursor: it should be readily available in bulk amounts, it should be simple to purify, evaporation needs to occur at temperatures significantly lower than its decomposition point, and last but not least, it should give $\mathrm{ZnO}$ directly without unwanted byproducts.

We decided to apply an alkyl-alkoxy zinc compound with heterocubane architecture as a precursor, and first investigated its properties. In particular, the methylzinc isopropoxide $\left[\mathrm{CH}_{3} \mathrm{ZnOCH}\left(\mathrm{CH}_{3}\right)_{2}\right]_{4}$ cluster, which has a central $\mathrm{Zn}_{4} \mathrm{O}_{4}$ framework, appeared to be a suitable molecular precursor for the formation of $\mathrm{ZnO}$ via simple elimination of propene and methane at a relatively low temperature. Its Xray structure was determined for the first time (cell parameters $\quad a=7.838(4) ; \quad b=9.468(6) ; \quad c=17.870(11) \AA$ A $; \quad \alpha=$ 77.457(12); $\quad \beta=77.806(19) ; \quad \gamma=73.211(12)^{\circ} ; \quad V=$ 1223.5(13) $\AA^{3} ; R=3.5 \%$; Cambridge Crystallographic Data Centre file CCDC 259836; www.ccdc.cam.ac.uk/data request/cif). In the current work we address the following points:

- Detailed study of the decomposition behavior and mechanism of the heterocubane.

- Investigation of the $\mathrm{ZnO}$ particle growth in the gas phase.

- Investigation of the purity of the CVS samples. 


\subsection{Decomposition Behavior of the Heterocubane}

To obtain a first impression about the decomposition of $\left[\mathrm{CH}_{3} \mathrm{ZnOCH}\left(\mathrm{CH}_{3}\right)_{2}\right]_{4}$, thermogravimetric analysis (TGA) was performed under an inert atmosphere (solid-state synthesis; SSS). At $200^{\circ} \mathrm{C}, 91 \%$ of the initial mass was lost, a fact which can only be explained by significant sublimation of the heterocubane at ambient pressure. However, there was no separate decomposition stage visible, and a brownish-black powder containing $\mathrm{ZnO}$ (according to powder $\mathrm{X}$ ray diffraction, PXRD) as well as significant amounts of elemental carbon were obtained. It can be concluded that inert atmospheric conditions are suitable to bring the heterocubane into the gas phase, but its conversion into pure $\mathrm{ZnO}$ cannot be achieved this way. To gain more knowledge about the sublimation behavior of the heterocubane, its vapor pressure $p$ was determined using a membrane-zero manometer (see Figure $1 \mathrm{a}$ and refs. $[34,35])$. At temperatures between 60 and $180^{\circ} \mathrm{C}$, a linear decrease of $p$ (plotted in logarithmic scale) against $1 / T$ is observed. At lower temperatures (below $40^{\circ} \mathrm{C}$ ), practically no heterocubane is present in the gas phase, and at higher temperatures (above $180^{\circ} \mathrm{C}$ ), in agreement with TGA, decomposition of the precursor takes place which leads to a strong increase in pressure. If, in a separate experiment, the heterocubane is held at a temperature higher than $50^{\circ} \mathrm{C}$ for a prolonged time $(24-48 \mathrm{~h}$ ), a slow but continuous increase of pressure is observed. This means that besides evaporation, above a certain temperature barrier simultaneous decomposition takes place. However, we conclude that this is due to solid-state decomposition, as the intact heterocubane can be fully recondensed from the gas phase. These investigations show that the sublimation of the heterocubane is determined by kinetic factors. This finding, and the fact that the total pressure is also influenced by gaseous products from the SSS, prevents the determination of thermodynamic parameters such as the sublimation enthalpy. It is nevertheless possible to control the amount of heterocubane in the gas phase by adjusting the temperature. The occurrence of significant amounts of carbon if the heterocubane is decomposed in argon could be a major drawback for the use of this precursor in CVS. Therefore, we investigated whether the quality of the products can be increased if the heterocubane is decomposed in an atmosphere containing oxygen $\left(20 \% \mathrm{O}_{2}+80 \% \mathrm{Ar}\right)$. Under TGA conditions (see Figure $1 \mathrm{~b}$ ), a slow decrease in mass $(1.6 \%)$ was detected between 70 and $130^{\circ} \mathrm{C}$, which can be attributed to the sublimation of the heterocubane. In contrast to the decomposition in argon, three well-defined decomposition phases followed. At the first $\left(T=133^{\circ} \mathrm{C}\right)$ the mass decreased by $8.6 \%$, then secondly by $25.7 \%$, with a maximum at $T=250{ }^{\circ} \mathrm{C}$. The decomposition was clearly finished at $T=420^{\circ} \mathrm{C}$ with a total mass loss of $44 \%$. This value fits quite well to the expected mass decrease from $\left[\mathrm{CH}_{3}\right.$ $\left.\mathrm{ZnOCH}\left(\mathrm{CH}_{3}\right)_{2}\right]_{4}$ to $\mathrm{ZnO}$ which is $41.63 \%$, and takes into
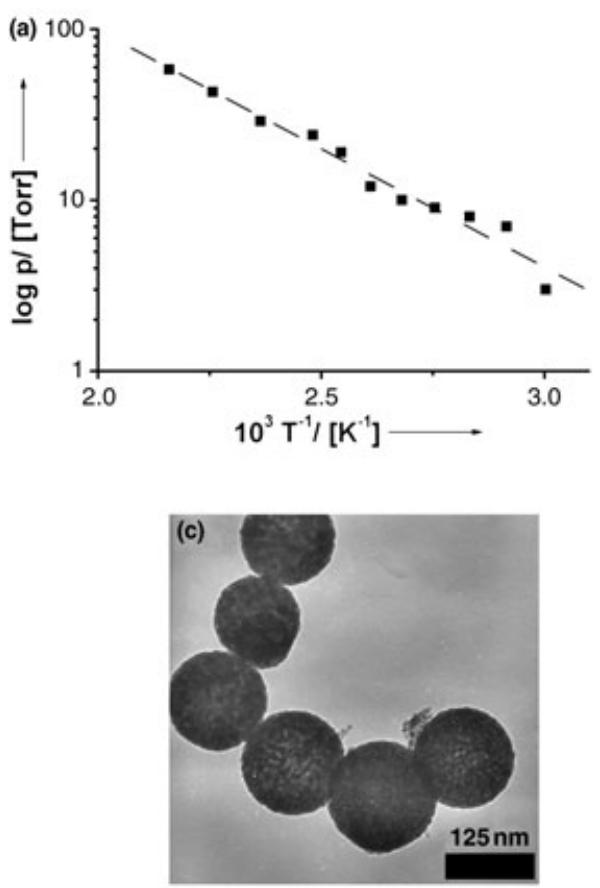

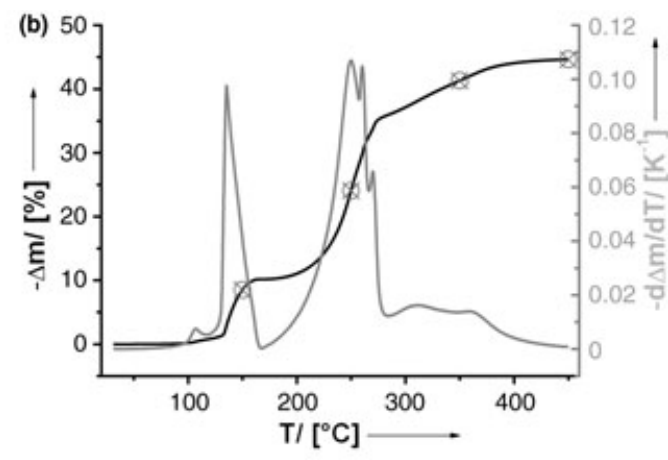

(d)

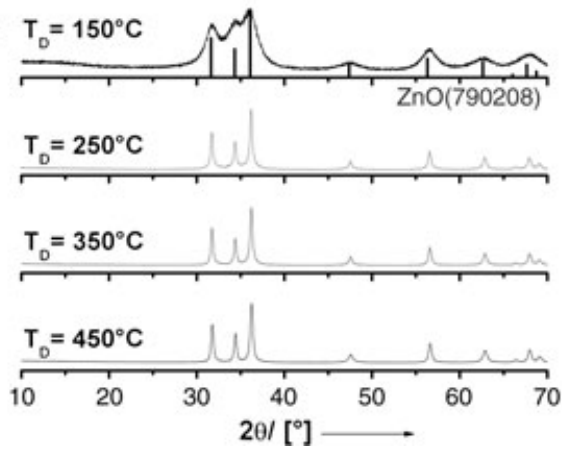

Figure 1. a) Results obtained from the determination of the vapor pressure of $\left[\mathrm{CH}_{3} \mathrm{ZnOCH}\left(\mathrm{CH}_{3}\right)_{2}\right]_{4}$. b) TGA of the solid-state decomposition of $\left[\mathrm{CH}_{3} \mathrm{ZnOCH}\left(\mathrm{CH}_{3}\right)_{2}\right]_{4}$ in an atmosphere containing $20 \%$ oxygen. For better visibility of the different decomposition stages, the second axis shows the DTA results. The four crosshairs indicate the points where, in a separate experiment, $\mathrm{ZnO}$ samples were prepared which were then investigated with PXRD. C) TEM images of one of these materials $\left(T=350^{\circ} \mathrm{C}\right)$ indicate unusual morphologies of $\mathrm{ZnO}$ nanoparticles aggregated to larger spheres. d) PXRD patterns of ZnO samples obtained at four different temperatures. account the previous sublimation of the heterocubane at low temperatures. The presence of oxygen has a profound impact on the solid-state synthesis. Instead of simultaneous sublimation and decomposition, sublimation was effectively suppressed, and three clear stages were identified. According to PXRD analysis, phasepure $\mathrm{ZnO}$ was obtained (Figure $1 \mathrm{~d}$ ) and no substantial carbon contamination (below 1\%) was found in elemental analysis. It should be mentioned that in a separate experiment, the heterocubane was heated to four different temperatures $\left(T_{\mathrm{D}}=\right.$ $150,250,350$, and $450^{\circ} \mathrm{C}$ ) to investigate the particle formation process in SSS. Figure $1 \mathrm{~d}$ shows the PXRD patterns for these four decomposition temperatures. In all cases $\mathrm{ZnO}$ was obtained, but the sample treated at only 
$150^{\circ} \mathrm{C}$ is characterized by much broader diffraction patterns, which indicates the formation of nanoscale $\mathrm{ZnO}$ particles of average crystallite size $(3.0 \mathrm{~nm})$, as determined by the Scherrer equation (calculated from the full width at half maximum (FWHM)). ${ }^{[36]}$ If the heterocubane is decomposed at $250^{\circ} \mathrm{C}$, particle growth to $\approx 25 \mathrm{~nm}$ occurs, and significant narrowing of the PXRD patterns can be observed. The size of the $\mathrm{ZnO}$ particles obtained from PXRD correlates well with TEM (Figure 1c). Interestingly, the single $\approx 25-\mathrm{nm} \mathrm{ZnO}$ nanoparticles are assembled into larger spherical aggregates of around 100-nm diameter. These results indicate that it is very difficult to obtain isolated, size-selected $\mathrm{ZnO}$ particles. Nevertheless, it can be concluded that to obtain pure $\mathrm{ZnO}$, the heterocubane should react in an oxygen-containing atmosphere. Therefore, the solid-state decomposition is useful to define the conditions that should be applied in CVS.

To test the latter, in CVS the heterocubane was evaporated in flowing $\mathrm{N}_{2}$ in a tube furnace, and oxygen was added to the aerosol directly in front of the decomposition furnace in which the heterocubane was finally decomposed at elevated temperatures (Figure 2). The decomposition under

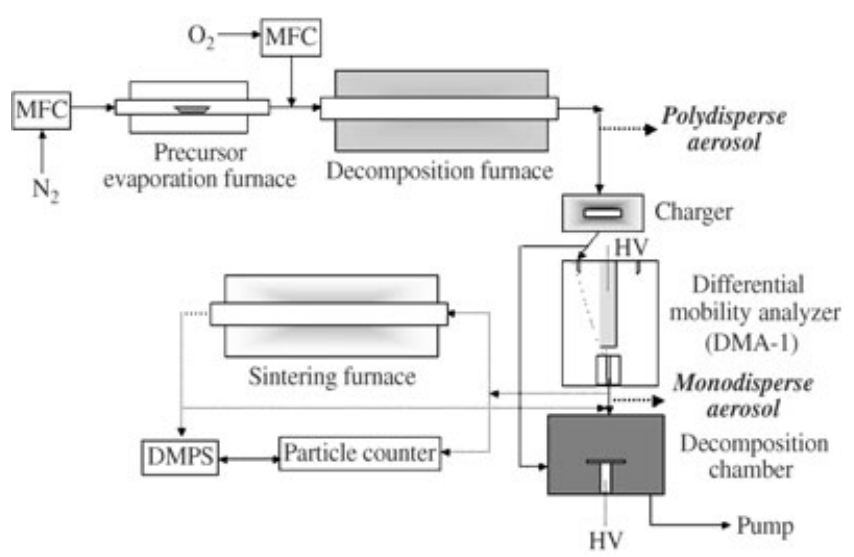

Figure 2. Schematic representation of the CVS setup.

CVS conditions is rather different from the solid-state decomposition, due to the fact that the precursor concentration is only at the parts per million (ppm) level; in the present study, the maximum precursor concentration was $\approx 12 \mathrm{ppm}$. A pronounced difference in particle-growth behavior can thus be expected.

Similar to the SSS experiments, the heterocubane was first treated in an inert atmosphere $\left(\mathrm{N}_{2}\right)$ to study the inherent ability of this particular precursor system, then the investigation of the effect of oxygen followed. The details of the CVS conditions are given in Table 1.

The PXRD pattern of the aerosol product obtained by decomposing the precursor at $300^{\circ} \mathrm{C}$ under an inert atmosphere (NZ300; see Table 1) is shown in Figure $3 \mathrm{a}$. The dif- fractogram clearly indicates the formation of nanocrystalline $\mathrm{ZnO}$. The average crystallite size obtained for NZ300 is $\approx 6 \mathrm{~nm}$. Figure $3 \mathrm{c}$ shows the TEM image of the polydisperse aerosol formed at $300^{\circ} \mathrm{C}(\mathrm{NZ300})$ in nitrogen. The micrograph indicates the formation of aggregates containing several tens of primary particles with diameters in the range of 5-10 $\mathrm{nm}$ and a mean primary-particle diameter of $\approx 6 \mathrm{~nm}$. Energy-dispersive X-ray (EDX) elemental analysis was performed on 20 different aggregates, which confirmed the presence of equal amounts of $\mathrm{Zn}: \mathrm{O}$ (within the error limit of $\pm 5 \%)$. The PXRD and TEM results confirm the formation of nanocrystalline $\mathrm{ZnO}$ from the precursor under an inert atmosphere, which is different to the SSS route where carbon-rich materials were obtained. However, this only accounts for the material that was retrieved from the deposition chamber (Figure 2). Interestingly, during the inert gas decomposition experiment at $300^{\circ} \mathrm{C}$, a gray deposit was found on the wall of the decomposition tube, where the aerosol leaves the decomposition zone and the temperature decreases to about $150^{\circ} \mathrm{C}$. The PXRD pattern of this gray product can be identified as representing a mixture of elemental $\mathrm{Zn}$ and $\mathrm{ZnO}$ (Figure $3 \mathrm{~b}$ ). The TEM image of the powder (Figure $3 \mathrm{~d}$ ) shows rod- and beltlike morphologies having diameters within $30-100 \mathrm{~nm}$ and typical lengths of a few hundred nanometers to micrometers. The EDX measurements on these "whiskers" confirm the presence of $\mathrm{Zn}$ only, and the electron diffraction patterns (not shown) prove their crystallinity. To the best of our knowledge there is as yet no report on the formation of " $\mathrm{Zn}$ whiskers" at such a low temperature. ${ }^{[37]}$ It can be suggested that the $\mathrm{Zn}$ whiskers grow by a vapor-solid (VS) mechanism caused by the high volatility of elemental zinc. This hypothesis is supported by findings recently published for $\mathrm{Zn}$ nanofibers prepared by evaporation of $\mathrm{Zn}$ powder. ${ }^{[37]}$ The TEM image (Figure $3 \mathrm{~d}$ ) also shows the presence of agglomerated particles with lower contrast. EDX measurements on these agglomerated particles indicate a 1:1 atomic ratio of zinc and oxygen. These smaller particles can be attributed to $\mathrm{ZnO}$, which was also found by PXRD. Therefore, $\mathrm{ZnO}$ and $\mathrm{Zn}$ did not form a nanocomposite but segregated on a macroscopic scale. The difference in distribution of $\mathrm{Zn}$ and $\mathrm{ZnO}$ can easily be explained by the different vapor pressures. Zinc remains in the gas phase inside the furnace because of its high vapor pressure and condenses at the coolest zone, the walls of the reactor, while exiting the decomposition furnace. Similar observations have been reported for metal 

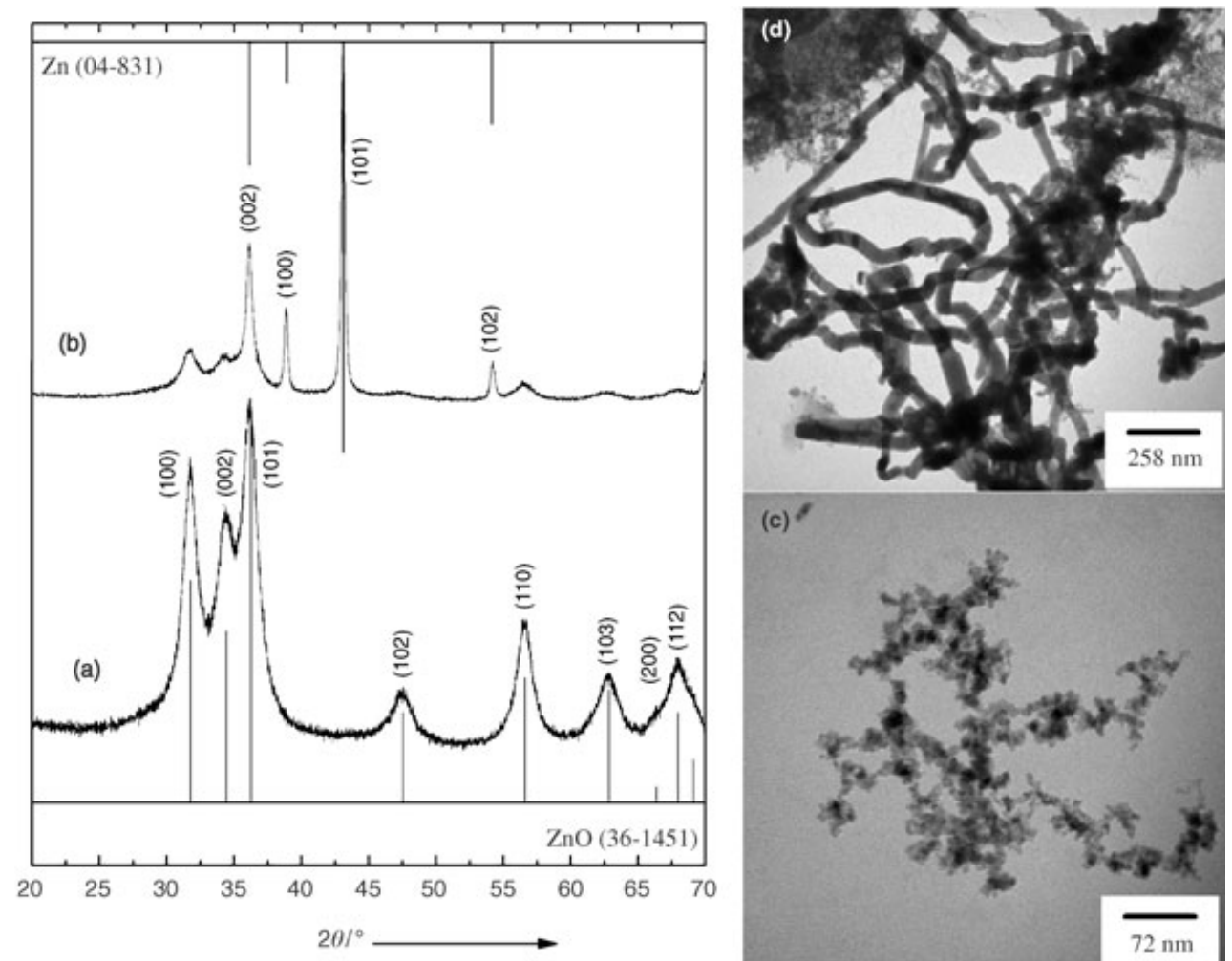

Subsequently, the unimolecular and collision-induced fragmentations of the mass-selected cations were investigated. It was possible to derive the following fragmentation mechanism (Scheme 1): upon electron ionization of the neutral heterocubane, no molecular ion $\left[\mathrm{CH}_{3}-\right.$ $\left.\mathrm{ZnOCH}\left(\mathrm{CH}_{3}\right)_{2}\right]_{4}{ }^{+\cdot}$ can be observed. Instead, the heaviest fragment of dissociative ionization is $\left[\left(\mathrm{CH}_{3}\right)_{3} \mathrm{Zn}_{4}\left(\mathrm{OCH}\left(\mathrm{CH}_{3}\right)_{2}\right)_{4}\right]^{+}$, which corresponds to the loss of one methyl group. Unimolecular disso-

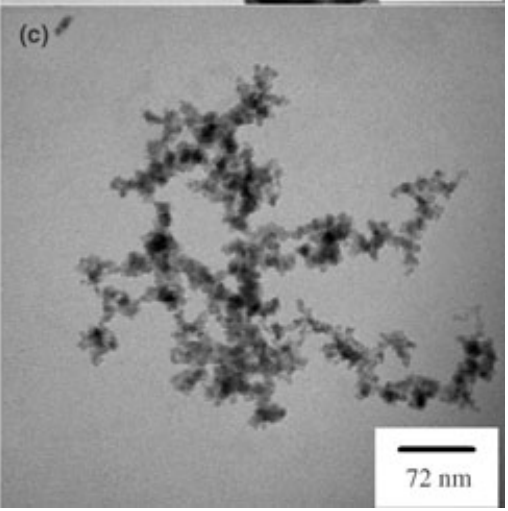

Figure 3. PXRD patterns and corresponding TEM images of CVS samples obtained in nitrogen (NZ300), collected in the deposition chamber $(a, c)$ and at the cold end of the reactor $(b, d)$. The reference diffraction patterns of $\mathrm{ZnO}$ and $\mathrm{Zn}$ are also given.

oxides with higher vapor pressures. ${ }^{[38,39]}$ While the above results provide a reasonable explanation for the distribution of the two materials $\mathrm{Zn}$ and $\mathrm{ZnO}$, the formation of $\mathrm{Zn}$ deserves particular attention as it is known that $\mathrm{ZnO}$ evaporates without homolytic cleavage, and, secondly, no formation of elemental zinc was found in the SSS. The results obtained from the SSS route are also in good agreement with MOCVD and solvothermal experiments using this precursor, in which the exclusive formation of $\mathrm{ZnO}$ was also found. ${ }^{[40]}$

Apparently, the precursor enables a second, yet not recognized, decomposition mechanism that results in the formation of elemental zinc. To address such a scenario in more detail, mass spectrometric studies were performed on the heterocubane. To this end, the heterocubane was ionized by electron ionization $(70 \mathrm{eV})$, and the cations formed were accelerated to $8 \mathrm{keV}$ kinetic energy and mass-selected by magnetic and electric sectors.
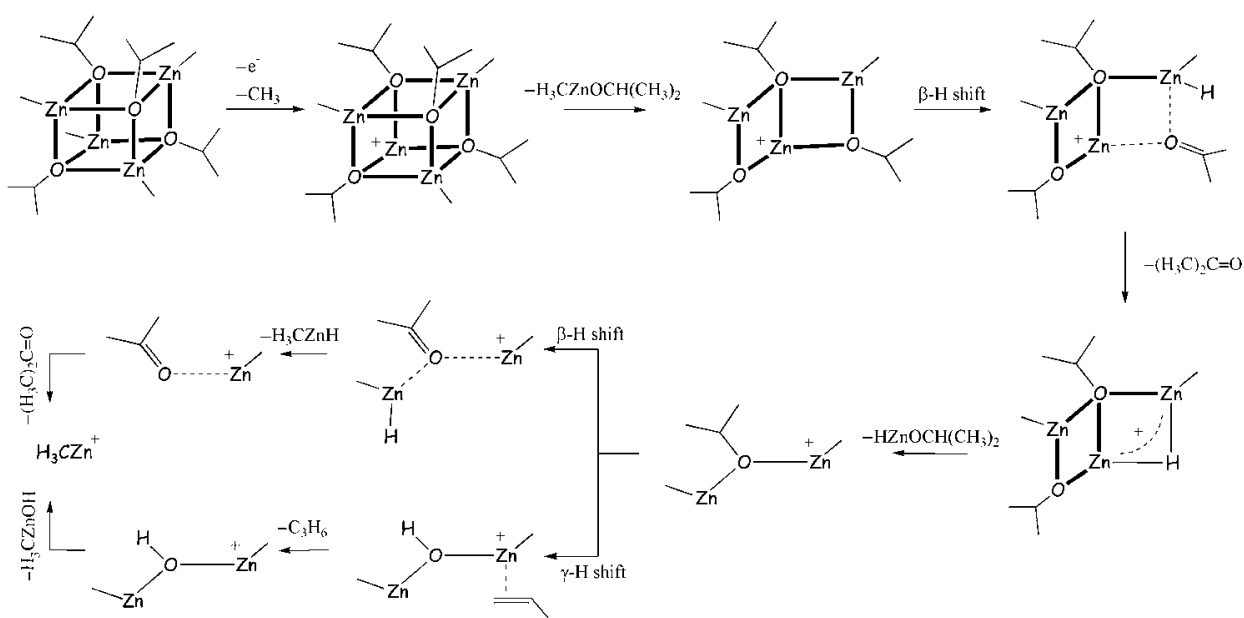

$\left[\left(\mathrm{CH}_{3}\right)_{3} \mathrm{Zn}_{4}\left(\mathrm{OCH}\left(\mathrm{CH}_{3}\right)_{2}\right)_{4}\right]^{+}$leads to cluster cleavage and the elimination of a neutral monomer unit $\left[\left(\mathrm{CH}_{3}\right) \mathrm{Zn}\left(\mathrm{OCH}\left(\mathrm{CH}_{3}\right)_{2}\right)\right]$ concomitant with the $\mathrm{Zn}_{3}$ cluster $\left[\left(\mathrm{CH}_{3}\right)_{2} \mathrm{Zn}_{3}\left(\mathrm{OCH}\left(\mathrm{CH}_{3}\right)_{2}\right)_{3}\right]^{+}$. Fragmentation of the latter occurs in two different ways: it either loses acetone, $\left(\mathrm{CH}_{3}\right)_{2} \mathrm{CO}$, or eliminates neutral $\mathrm{MeZnH}$. Both products can be accounted for by involving an initial $\beta$-hydrogen transfer from the zinc-bound isopropoxy unit to the zinc atom, a process for which previous evidence exists in the gasphase chemistry of transition-metal alkoxides. ${ }^{[41-45]}$ Apparently, it is possible to a certain extent that the $\mathrm{CH}$ carbon atom attached to the oxygen atom can be oxidized from the formal oxidation state +0 (in the isopropoxide) to +2 (in acetone), accompanied by a hydride transfer to the $\mathrm{Zn}$ atom. Likewise, the fragment ion $\left[\mathrm{Me}_{2} \mathrm{Zn}_{3}\left(\mathrm{OCH}\left(\mathrm{CH}_{3}\right)_{2}\right)_{2}(\mathrm{H})\right]^{+}$undergoes loss of neutral $\left[\mathrm{HZn}\left(\mathrm{OCH}\left(\mathrm{CH}_{3}\right)_{2}\right)\right]$ concomitant with $\left[\mathrm{Me}_{2} \mathrm{Zn}_{2^{-}}\right.$ $\left.\left(\mathrm{OCH}\left(\mathrm{CH}_{3}\right)_{2}\right)\right]^{+}$, which then shows loss of $\mathrm{MeZnH}$ as the major fragmentation pathway to afford the mononuclear

Scheme 1. Mechanistic investigation of the gas-phase decomposition of $\left[\mathrm{CH}_{3} \mathrm{ZnOCH}\left(\mathrm{CH}_{3}\right)_{2}\right]_{4}$. 
cation $\left[\mathrm{MeZn}\left(\mathrm{OC}\left(\mathrm{CH}_{3}\right)_{2}\right)\right]^{+}$. The latter finally eliminates acetone and furnishes $\mathrm{CH}_{3} \mathrm{ZnH}$. The generation of $\mathrm{CH}_{3} \mathrm{ZnH}$ is remarkable because it can explain the formation of elemental $\mathrm{Zn}$ in the gas-phase decomposition of the heterocubane via the final decomposition step $\mathrm{CH}_{3} \mathrm{ZnH} \rightarrow \mathrm{Zn}+\mathrm{CH}_{4}$.

It may be questionable whether the proposed mechanism for the formation of $\mathrm{Zn}$ is valid for CVS, since the reaction cascades in the mass spectrometer are initiated by ionization. Therefore, (TGA-)MS measurements were performed in combination with the thermogravimetric decomposition of the heterocubane in an inert atmosphere discussed above. In fact, besides the expected volatile products propene and methane, which imply the formation of $\mathrm{ZnO}$, a significant amount of acetone could also be detected. Hence, it seems very likely that the proposed mechanism is indeed responsible for the formation of elemental zinc under CVS conditions.

\subsection{Particle Growth Investigation}

The SSS gave phase-pure $\mathrm{ZnO}$ materials if prepared under an oxygen-containing atmosphere, therefore the CVS was conducted under analogous conditions $\left(20 \% \mathrm{O}_{2}\right)$. The PXRD patterns of the aerosol product obtained by decomposition of the precursor at different temperatures are shown in Figure $4 \mathrm{a}-\mathrm{d}$. The diffractograms clearly indicate the formation of hexagonal $\mathrm{ZnO}$ and the absence of any crystalline impurities in the samples. At relatively low decomposition temperatures $\left(T=300^{\circ} \mathrm{C}\right)$, the PXRD peaks are quite broad. With increasing decomposition temperatures, the widths of the peaks decrease in conjunction with a strong increase of their intensities. This observation indicates that the crystallite size of the product increases with higher decomposition temperatures (Table 1). Figure $4 \mathrm{e}-\mathrm{h}$ shows the TEM images of the polydisperse aerosol formed at different temperatures under oxidizing conditions. The micrographs show the formation of aggregates containing several dozen primary particles in the OZ300 and OZ500 samples (Figure $4 \mathrm{e}$ and $\mathrm{f}$ ).

Most of the primary particles obtained at these temperatures are in the range of 5-14 $\mathrm{nm}$. Both the XRD and TEM results indicate that crystallite sizes do not change much with an increase in temperature from 300 to $500^{\circ} \mathrm{C}$, whereas a further increase of temperature from 500 to $750^{\circ} \mathrm{C}$ leads to a large change in crystallite sizes. This is probably a result of sintering of the particles formed at high temperatures. Increasing the decomposition temperature further to $750^{\circ} \mathrm{C}$ leads to the collapse of the aggregates and, due to sintering processes, formation of larger, compact particles (Figure $4 \mathrm{~g}$ ). Similar results were obtained at $900^{\circ} \mathrm{C}$ (Figure $4 \mathrm{~h}$ ). The evolution of particles is apparently very different in SSS and CVS. While in SSS it seemed very difficult to control particle size and purity because of the low temperatures required for small particles, in CVS it appears that control over particle size can be obtained even at relatively high temperatures. This conclusion leads to the question whether or not the current system is suitable for an investigation of particle generation and growth processes in aerosols of metal oxides. We believe that this question is rather important because many approaches for preparing metal oxides involve aerosol methods. The PXRD and TEM results shown in Figure 4 demonstrate how $\mathrm{ZnO}$ particles evolve from small primary particles $(\approx 8 \mathrm{~nm}$ in OZ300) to large aggregates, and then from aggregates to larger particles $(\approx 29 \mathrm{~nm}$ in OZ900) due to thermal effects. To understand the nucleation, growth, aggregation, and sintering mechanism of the particles inside the decomposition furnace, more thorough investigations were performed and the details are give in this section.
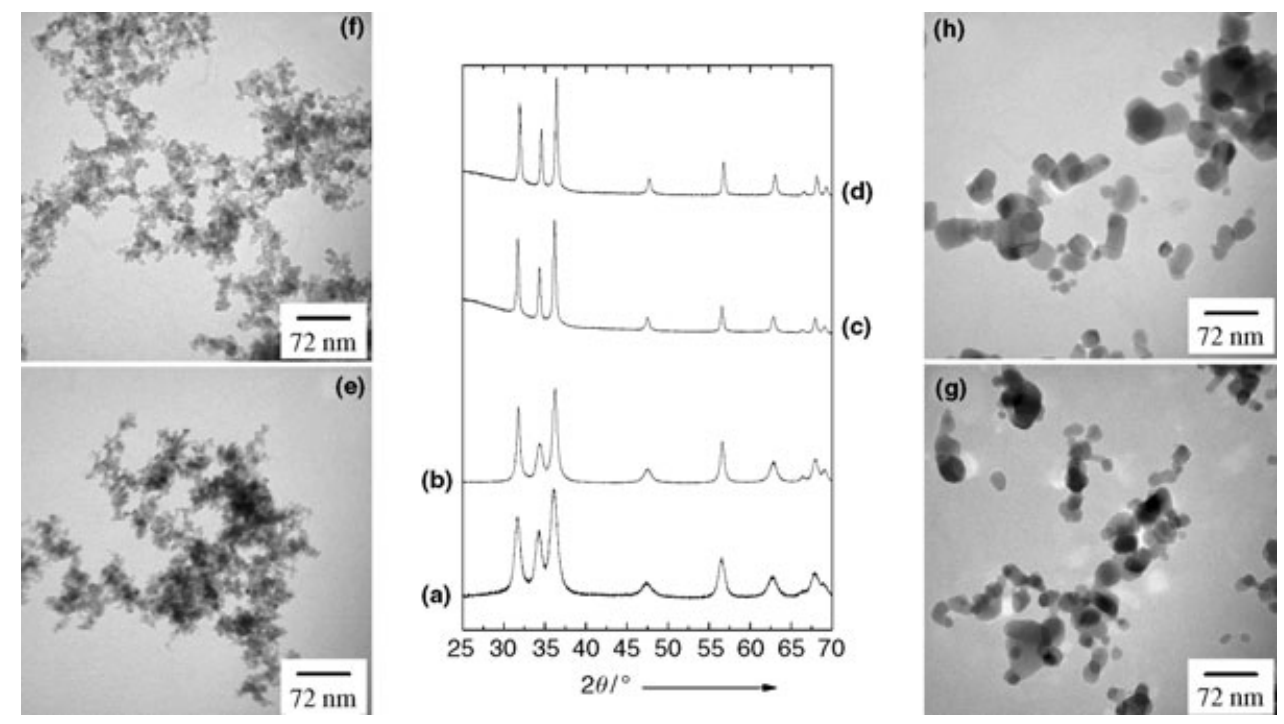

Figure 4. TEM images and PXRD patterns for CVS samples obtained at different temperatures in oxygen-containing atmospheres (20\%). a), e) Samples at $\left.\left.T=300^{\circ} \mathrm{C}, \mathrm{b}\right), \mathrm{f}\right)$ at $\left.\left.T=500^{\circ} \mathrm{C}, \mathrm{c}\right), \mathrm{g}\right)$ at $T=750^{\circ} \mathrm{C}$, and d), h) at $T=900^{\circ} \mathrm{C}$.
Generally, the transformation of the organometallic precursor vapor to the final particles is a complex chemical and physical process. It involves vapor-phase chemical reaction, nucleation of the supersaturated vapor to form primary particles, primary-particle growth by vapor condensation and/or heterogeneous chemical reactions, coagulation by particle-particle collisions induced by their Brownian motion, and coalescence or sintering between particles. ${ }^{[46,47]}$ For many metal oxides produced by oxidation of organometallic precursors using aerosol reactors or in flames, it has been 
found that nucleation of the oxide species is virtually instantaneous due to the very rapid oxidation and high concentration of the precursor vapor, and only the physical coagulation and coalescence process determine the final particle morphology. ${ }^{[47,48]}$ In the present study this was verified by increasing the precursor vapor pressure through increasing the evaporation temperature and keeping the decomposition furnace temperature constant at $300^{\circ} \mathrm{C}$ to minimize any postsintering effect. A differential mobility analyzer (DMA) and condensation nucleus counter ( $\mathrm{CNC}$ ) were used to perform in situ measurements of the agglomerate mobility distribution with different precursor concentrations. When performing electrical mobility measurements, the classified mobility (mobility equivalent diameter, $D_{\mathrm{m}}$ ) of the fractal-like aggregate is proportional to its projected area. ${ }^{[46,49]}$ The results obtained from the mobility scan using the DMA and CNC showed that the geometric mean $D_{\mathrm{m}}$ values of the aggregates increase with an increase in precursor evaporation temperatures. The change in precursor vapor pressure (Figure 1a) does not result in any substantial change in the primary-particle diameters as proven by TEM. The results obtained from the change in $D_{\mathrm{m}}$ together with the unchanged primary size diameters indicate that only the number of primary particles in an individual aggregate increases. Thus, heterogeneous reactions do not play any role in the primary-particle growth and coagulation and/or coalescence determine the morphology of the final product.

The initial oxidation of the precursor vapor leads to the formation of highly reactive $\mathrm{ZnO}$ species, and collisions between them will take place due to Brownian motion. When the particle size is very small it is generally assumed that whenever two spherical particles collide they form a larger, spherical particle, that is, coalescence is instantaneous. ${ }^{[4]}$ This is possible due to an enhanced surface diffusion coefficient, which results in a significant decrease in sintering time for clusters only few nanometers in size. ${ }^{[47,50]}$ However, as the particles grow larger, this assumption fails, since the particle coalescence rate is no longer "instantaneous". Thus, beyond a critical size the particles stop
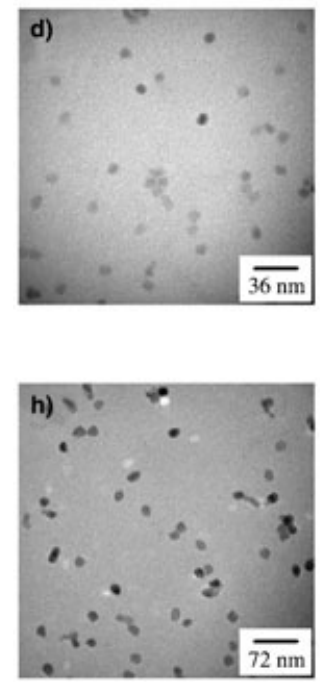

growing by instantaneous coagulation-coalescence and fractal-like aggregates begin to form. This can be seen for samples OZ300 and OZ500 (Figure 5). The sintering of these agglomerated particles can also take place simultaneously in the decomposition furnace, although the extent of sintering is quite low up to $500^{\circ} \mathrm{C}$ as discussed below. Upon increasing the temperature of the decomposition furnace, further sintering of the agglomerated particles takes place. This scenario accounts for the fully sintered particles observed at 750 and $900^{\circ} \mathrm{C}$ (Figure $4 \mathrm{~g}-\mathrm{h}$ ). Sintering of a material depends on many parameters, such as the temperature of the reactor, residence time inside the reactor, particle diameter, and fundamental physical properties of the particles. Thus, knowledge of the details of the time-temperature history in a reactor is very important. Although decomposition of the precursor at 750 or $900^{\circ} \mathrm{C}$ gives sintered $\mathrm{ZnO}$ particles, it is still very difficult to separate out the sintering process from other processes such as chemical reactions, nucleation, or coagulation-coalescence. To obtain a more quantitative picture about the growth of aerosol particles of $\mathrm{ZnO}$ (and metal oxides in general), it is at least necessary to separate the chemical processes from the pure sintering processes in space and/or time. To this end, particles were generated at low temperature $\left(\right.$ at $\left.300^{\circ} \mathrm{C}\right)$, classified, and sintered in an-
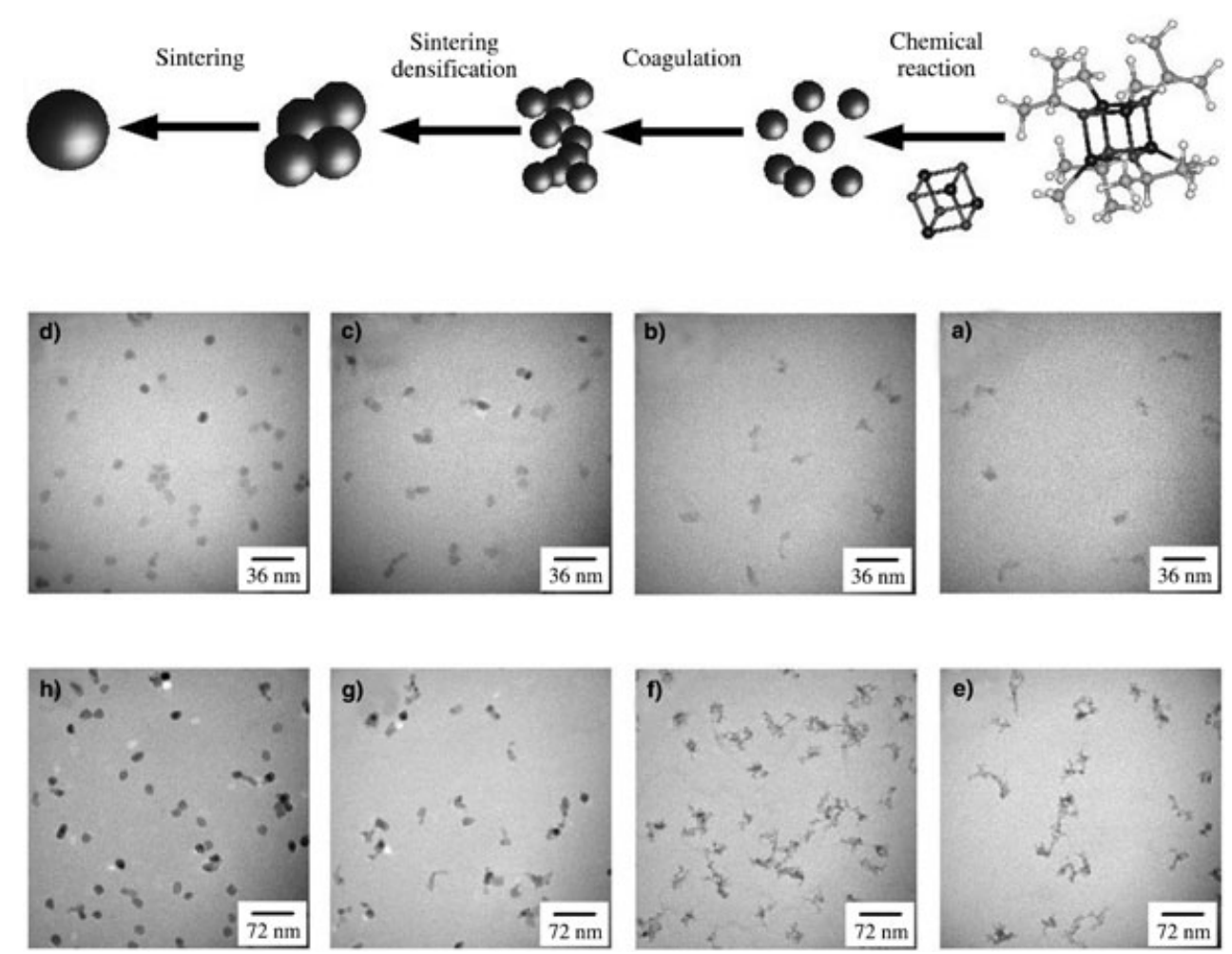

Figure 5. Left: a schematic representation of the morphological genesis of the CVS ZnO particles. The chemical "strip" of the heterocubane leads to highly reactive " $\mathrm{Zn}_{4} \mathrm{O}_{4}$ " clusters (leaving organic groups are not shown). These species can be regarded as highly reactive $\mathrm{ZnO}$ monomers which, due to collisions between clusters, lead to the formation of primary particles of $\mathrm{ZnO}$. These primary particles still have a very high interface energy, and undergo facile aggregation to larger particles. The primary particles fuse together at higher temperatures to form secondary particles via sintering densification. Finally, the secondary particles also sinter together to give the final single particle. a-d) TEM images for such a series of particle evolution steps for initial agglomerates with a $D_{\mathrm{m}}$ of $15 \mathrm{~nm}$, and e-h) for initial agglomerates with a $D_{\mathrm{m}}$ of $30 \mathrm{~nm}$. 
other furnace at different temperatures (see Figure 2). Interaction among agglomerates in the sintering furnace, such as coagulation, can be neglected because of the sufficiently low concentration $\left(\approx 5 \times 10^{4}\right.$ particles/cc $)$ of the agglomerates in the gas phase. As the purity of the particles is very high as proven later, impurity effects in the sintering process can be neglected. Thus, the reduction of surface area (or $D_{\mathrm{m}}$ ) and diameter of the particles can be measured (by DMA-CNC and TEM) without concern for other phenomena that would influence the sintering rate. Figure $5 \mathrm{a}-\mathrm{d}$ show the changes of morphology of size-classified agglomerates of 15$\mathrm{nm}$ mobility equivalent diameter $\left(D_{\mathrm{m}}\right)$, obtained by the first DMA, at different temperatures $\left(300,500,750\right.$, and $\left.900^{\circ} \mathrm{C}\right)$. Figure $5 \mathrm{e}-\mathrm{h}$ show a second example of sintering of agglomerates starting with a $D_{\mathrm{m}}$ of $30 \mathrm{~nm}$. These images indicate that the agglomerates consist of primary particles which do not show any noticeable change in morphology till $500^{\circ} \mathrm{C}$. On increasing the sintering temperature to $750^{\circ} \mathrm{C}$, the agglomerates start to fuse into single spherical particles, and at $900^{\circ} \mathrm{C}$ the particles are fully compact, that is, sintering is complete. The change of $D_{\mathrm{m}}$ of $\mathrm{ZnO}$ agglomerates with different sintering temperatures for four different initial sizes is shown in Figure 6. Below $500^{\circ} \mathrm{C}$, there is only a slight decrease in $D_{\mathrm{m}}$. From 500 to $800^{\circ} \mathrm{C}$, there is a rapid decrease in $D_{\mathrm{m}}$ which is due to densification of the agglomerates. A further increase of the sintering temperature to $1000^{\circ} \mathrm{C}$ leads to only a small change in $D_{\mathrm{m}}$. In comparison, the TEM results show a very good correlation with $D_{\mathrm{m}}$ scan results. To understand the influence of temperature, residence time, and particle sizes on the sintering of the $\mathrm{ZnO}$ particles, it is important to identify the mechanism(s) contributing to the particle growth and compaction. Various stages and

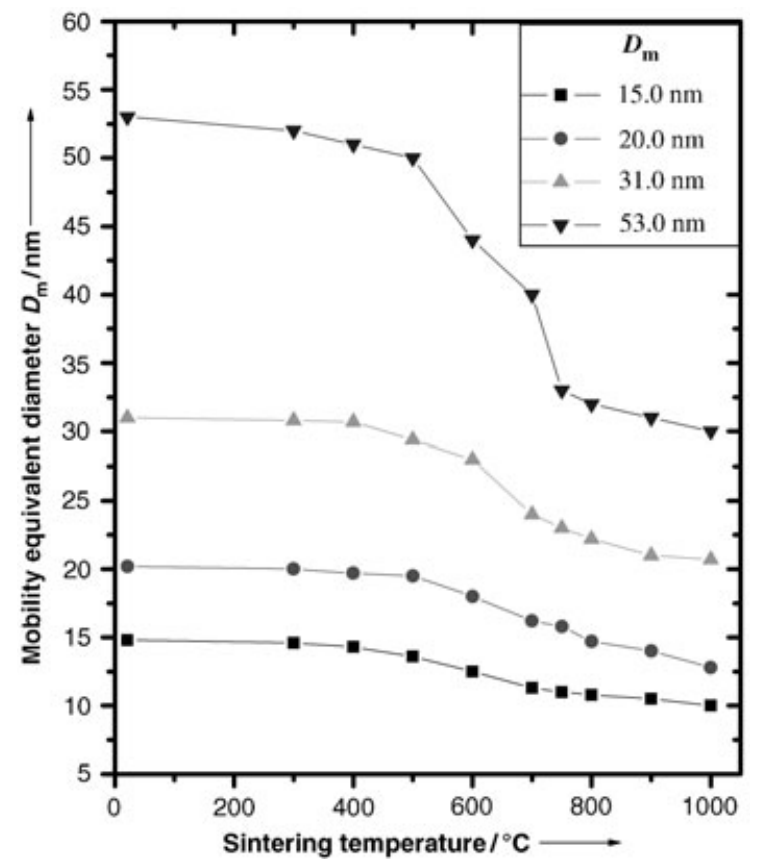

Figure 6. Change of mobility equivalent diameter $\left(D_{\mathrm{m}}\right)$ of $\mathrm{ZnO}$ agglomerates as a function of the sintering temperature for four different initial sizes. mass transport mechanisms have been proposed to contribute to sintering. ${ }^{[51]}$ The main mass-transport processes that determine solid-state sintering are surface diffusion, volume diffusion, grain-boundary diffusion, viscous flow, and evaporation-condensation. ${ }^{[51,52]}$ The most accepted expression to calculate the characteristic sintering time, $\tau$, is derived for the initial stage of sintering from the two-sphere model with the assumption that it holds true for all stages of sintering. ${ }^{[46-48,51-53]}$ To calculate $\tau$, it is important to determine the rate-controlling transport mechanism(s) for sintering. $\mathrm{ZnO}$ has a melting point of $1975^{\circ} \mathrm{C}$, and it is therefore rather unlikely that viscous flow plays any significant role in the sintering mechanism for $T \leq 900^{\circ} \mathrm{C}$ as in our experiments. The evaporation-condensation mechanism can also be neglected due to the very low vapor pressure of $\mathrm{ZnO}$ in this temperature range. ${ }^{[54]}$ Surface diffusion plays an important role only in the initial stage of neck formation, but it does not contribute to the densification and, thus, its contribution to sintering was neglected, in agreement with the literature. ${ }^{[53,54]}$ Therefore, in all subsequent calculations only grain-boundary and volume diffusions were further considered as the sintering mechanism. To determine the time needed for two $\mathrm{ZnO}$ particles to sinter by grain-boundary diffusion $\left(\tau_{\mathrm{GB}}\right)$, the relation given by Kobata et al. was used, ${ }^{[55]}$ which was successfully applied previously for various other systems: ${ }^{[46,48,56,57]}$

$\tau_{\mathrm{GB}}=\frac{\left(0.013 k_{\mathrm{B}} T r_{\mathrm{i}}^{4}\right)}{b D_{\mathrm{GB}} \gamma v}$

where $k_{\mathrm{B}}$ is the Boltzmann constant, $T$ is the sintering furnace temperature, $r_{\mathrm{i}}$ is the radius of the primary particles, $b$ is the grain-boundary width, $D_{\mathrm{GB}}$ is the grain-boundary diffusion coefficient, $\gamma$ is the surface tension, and $v$ is the atomic volume. The above relation has been derived for ( $2 \mathrm{l} /$ $\left.D_{\mathrm{pi}}\right)=0.83$, where $l$ is the neck radius and $D_{\mathrm{pi}}$ the initial primary-particle diameter, and assumes that the grain-boundary width remains constant during the coalescence process. The literature values of $b D_{\mathrm{GB}},{ }^{[58]} \gamma,{ }^{[59,60]}$ and $v$ are listed in Table 2. To the best of our knowledge, there is only one report on the grain-boundary diffusion coefficients for $\mathrm{ZnO}{ }^{[58]}$ Based on that report, it was possible to calculate $\tau_{\mathrm{GB}}$ values after extrapolating the grain-boundary diffusion coefficient in the studied temperature range. The grainboundary diffusion coefficient of zinc was used for calculation because of the much higher diffusivity value of zinc

Table 2. Physical properties of $\mathrm{ZnO}$ used in the present calculations.

\begin{tabular}{|c|c|c|}
\hline Properties & Values & References \\
\hline $\begin{array}{l}\text { Melting point }\left(T_{m} \text {, }\right. \\
\text { bulk) }\end{array}$ & $1975^{\circ} \mathrm{C}$ & [56] \\
\hline Molecular weight $(M)$ & 81.37 & [56] \\
\hline Density $(\rho)$ & $5.6 \mathrm{~g} \mathrm{~cm}^{-3}$ & [56] \\
\hline Atomic volume $(v)$ & $2.4 \times 10^{-29} \mathrm{~m}^{3}$ & \\
\hline Surface tension $(\gamma)$ & $0.735 \mathrm{~J} \mathrm{~m}^{-2}$ & {$[60,61]$} \\
\hline$b D_{\mathrm{GB}}$ (see text) & $\begin{array}{l}1.59 \times 10^{-12} \exp [-(235.14 \mathrm{KJ}) / \\
\mathrm{RT}] \mathrm{m}^{3} \mathrm{~s}\end{array}$ & [59] \\
\hline$D_{\mathrm{VD}}$ (see text) & $1.7 \times 10^{-7} \exp [-(256.34 \mathrm{~kJ}) / \mathrm{RT}] \mathrm{m}^{2} \mathrm{~s}$ & s[59] \\
\hline
\end{tabular}


compared to that of oxygen. ${ }^{[58,61]}$ Figure 7 a shows the dependence of the primary-particle diameter $\left(D_{\mathrm{pi}}=2 r_{\mathrm{i}}\right)$ on $\tau_{\mathrm{GB}}$ as a function of temperature. The experimental residence times in the sintering furnace at $25^{\circ} \mathrm{C}(4.6 \mathrm{~s})$ and $1000^{\circ} \mathrm{C}$ (1.1 s) are also shown in Figure $7 \mathrm{a}$ and it should be noted that the residence time decreases with an increase in sintering temperature. $\tau_{\mathrm{GB}}$ values increase with an increase in primary-particle diameter (Figure 7a) and decrease with increase in sintering temperature. Figure 7 a reveals that, with the present experimental residence time, sintering due to grain-boundary diffusion cannot be observed below $500^{\circ} \mathrm{C}$ for particles $>6 \mathrm{~nm}$ in diameter. Since the mean primary-
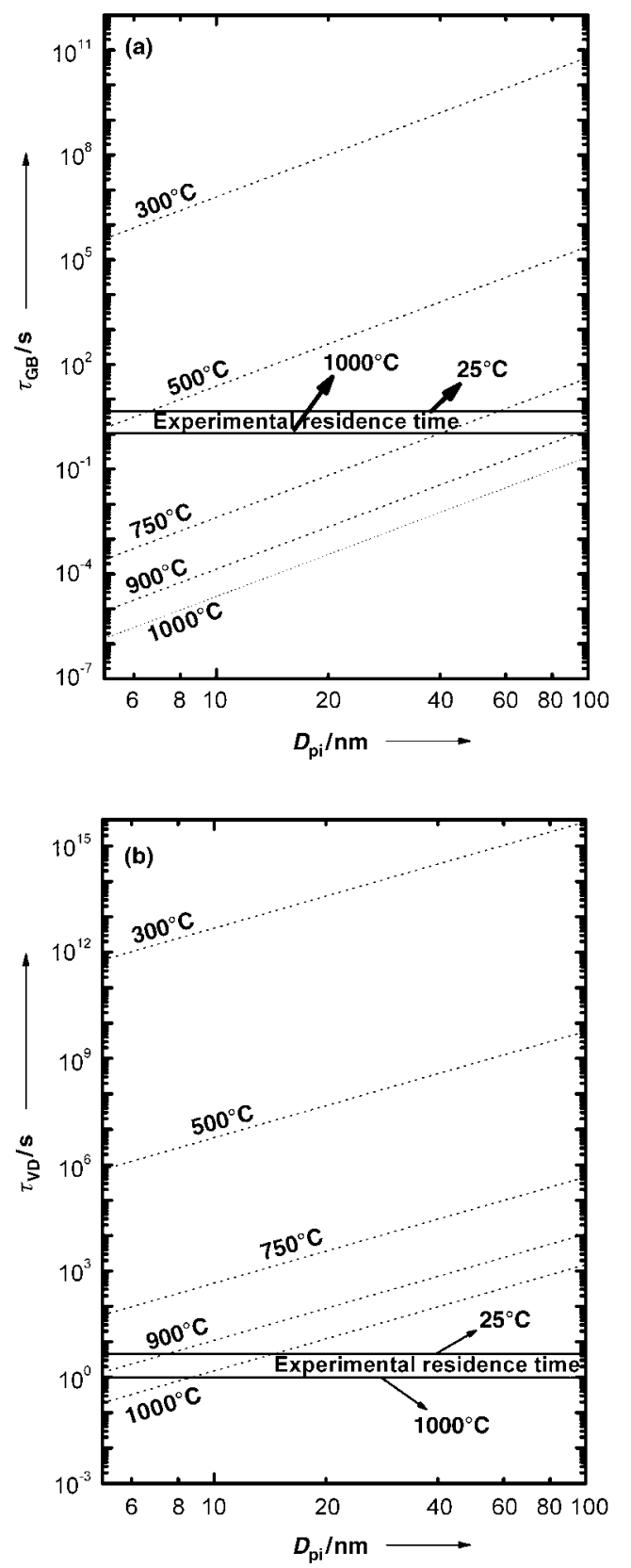

Figure 7. Change of the characteristic sintering time as a function of temperature and initial primary-particle diameter $\left(D_{\mathrm{p}}\right)$, a) for grainboundary diffusion $\tau_{G B}$ and b) for volume diffusion $\tau_{V D}$. particle diameter of $\mathrm{ZnO}$ agglomerates obtained at $300{ }^{\circ} \mathrm{C}$ is $\approx 8 \mathrm{~nm}$ (see Table 1), and according to Figure $7 \mathrm{a}$, these can be sintered at $750^{\circ} \mathrm{C}$, which is consistent with the experimental findings (see Figures 5 and 6). Accordingly, grainboundary diffusion can be identified as a reasonable mechanism responsible for sintering of $\mathrm{ZnO}$ primary particles. The characteristic sintering time of coalescence by volume diffusion, $\tau_{\mathrm{VD}}$, was calculated using the relation given by Friedlander et al..:[62]

$\tau_{\mathrm{VD}}=\frac{\left(k_{\mathrm{B}} T r_{\mathrm{i}}^{3}\right)}{\left(16 D_{\mathrm{VD}} \gamma v\right)}$

where $D_{\mathrm{VD}}$ is the volume diffusion coefficient of the diffusing species. Values of the different physical parameters are given in Table 2. Several groups have reported the diffusivity of zinc in $\mathrm{ZnO} ;{ }^{[63]}$ for the present work we used the Arrhenius equation recently reported by Nogueira at al., which is in good agreement with results from other groups. ${ }^{[58]}$ Figure $7 \mathrm{~b}$ shows the primary-particle diameter $\left(D_{\mathrm{pi}}\right)$ dependency of $\tau_{\mathrm{VD}}$ as a function of temperature. The experimental residence times in the sintering furnace at $25^{\circ} \mathrm{C}$ and $1000^{\circ} \mathrm{C}$ are also shown for comparison. Figure $7 \mathrm{~b}$ shows that primary particles with a diameter of $8 \mathrm{~nm}$ cannot be sintered by diffusional sintering at $750{ }^{\circ} \mathrm{C}$ or even at $900^{\circ} \mathrm{C}$ within the present experimental residence times. Comparison of Figure $7 \mathrm{a}$ and $\mathrm{b}$ implies that, for a certain primary-particle diameter and at a certain temperature, $\tau_{\mathrm{VD}}$ exceeds $\tau_{\mathrm{GB}}$ by a factor of $10^{5}$. These results suggest that the grain-boundary diffusion of zinc controlled the rate of diffusional sintering in the present study. Recently, Hynes et al. ${ }^{[54]}$ reported that $95-98 \%$ theoretical density was achieved on isothermal sintering of nanophase undoped $\mathrm{ZnO}$ at $650-700^{\circ} \mathrm{C}$ for $40 \mathrm{~min}$. This result is in good agreement with the proposed model in the present study. In conclusion, the results concerning the sintering of the $\mathrm{ZnO}$ aerosol presented above demonstrate that it is possible not only to nicely control the size of the semiconductor nanoparticles, but also to understand their formation on a much more fundamental basis.

\subsection{Investigation of Sample Purity}

It has already been mentioned that an additional advantage of the gas-phase synthesis in comparison to the solidstate synthesis could be that products of higher purity can be obtained. It is clear that not only the morphology (size and shape) of semiconductors will influence their properties, but also the compositional and microstructural purity is of extraordinary importance. Therefore, the purity of the materials obtained from CVS was studied and compared to that of the SSS samples. However, it appears meaningless to compare samples according to the temperature of preparation because concentration, as well as mobility and residence time, is extremely different in the CVS and SSS routes. Therefore, samples of similar $\mathrm{ZnO}$ particle size were compared with each other. Figure 8 a shows the ${ }^{13} \mathrm{C}$ magicangle spinning (MAS) NMR spectrum of an SSS sample 
with average particle size of $25 \mathrm{~nm}$. After 20000 scans, weak but nevertheless clear signals at 180.7, 169.0, and $20.0 \mathrm{ppm}$ were observed. We assign the deep-field signals to the occurrence of surface-bound carboxylate species. Even upon treatment at higher temperature, it was difficult to remove these carboxylates, while the high-field signal disappeared. We therefore, attribute the signal at $20 \mathrm{ppm}$ to $\mathrm{C}-\mathrm{H}$ species. It has already been shown above that in CVS it is possible to go to significantly higher temperatures than for SSS
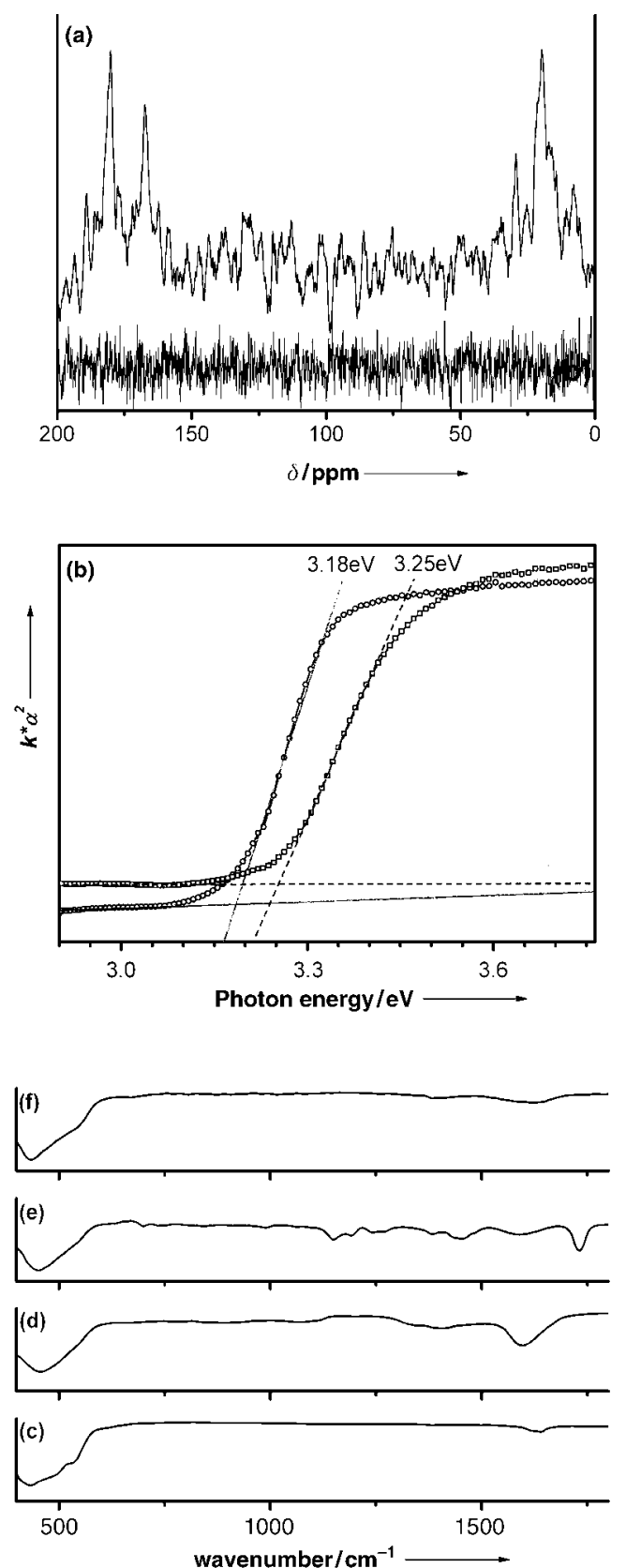

Figure 8. a) ${ }^{13} \mathrm{C}$ MAS NMR spectra of ZnO samples of comparable particle size $(\approx 25 \mathrm{~nm})$ via SSS (upper curve) in comparison to CVS (OZ750; lower curve). b) UV/Vis spectra of two samples obtained by CVS. c-f) FIIR spectra: c) commercial ZnO as reference; d) SSS sample; e) CVS sample (OZ300); f) CVS sample (OZ750). g) UV/Vis spectra of CVS samples with two different particle sizes ( 5 and $12 \mathrm{~nm})$. while particle growth is restricted. Accordingly, sample OZ750 (Table 1) also possesses an average particle size of $\approx 25 \mathrm{~nm}$, and can be compared best to the SSS sample. Comparing Figure $8 \mathrm{a}$ and $\mathrm{b}$ demonstrates that there is no detectable signal for ${ }^{13} \mathrm{C}$ in the CVS sample. This finding indicates that the CVS sample is free of organic impurities.

To support this conclusion, FTIR spectra of different samples were recorded and referenced to the spectrum of commercial $\mathrm{ZnO}$ (Figure 8c) with the most intense band at $\tilde{v}=440 \mathrm{~cm}^{-1}$. The IR spectra of the SSS sample (Figure $8 \mathrm{~d}$ ) confirm the presence of carboxylate species by the strong band at $1600 \mathrm{~cm}^{-1}$, in good agreement with the ${ }^{13} \mathrm{C}$ MAS NMR studies. Two CVS samples were measured for comparison. One sample (Figure $8 \mathrm{e}$ ) was prepared at a temperature (OZ300) comparable to that of the SSS sample. Various bands at $\tilde{v}=1730,1588,1452,1387,1245,1192,1149$, 698 , and $445 \mathrm{~cm}^{-1}$ are present. Hence, a temperature of $300{ }^{\circ} \mathrm{C}$ is insufficient for removal of all remaining organic impurities from the $\mathrm{ZnO}$ sample. A key advantage of the CVS procedure is therefore that it enables higher process temperatures. In fact, the CVS sample prepared at $750^{\circ} \mathrm{C}$ was free of organic impurities (Figure $8 \mathrm{f}$ ).

Finally, two samples of different particle size (5 and $12 \mathrm{~nm}$ ) obtained by CVS were investigated by UV/Vis spectroscopy in reflection mode (see Figure $8 \mathrm{~g}$ ). The determination of the bandgap revealed $3.18 \mathrm{eV}$ for the $5-\mathrm{nm}$ sample and $3.25 \mathrm{eV}$ for the $12-\mathrm{nm}$ sample. The red-shift of the absorption edge in comparison to the literature value of $\mathrm{ZnO}(3.30 \mathrm{eV})$ cannot be explained by quantum size effects, ${ }^{[64]}$ but is reasonably explained by the occurrence of shallow donor levels introduced by impurity atoms such as carbon.

Room-temperature photoluminescence (PL) spectra were recorded to investigate the presence of oxygen defects. Depending on the preparation technique, $\mathrm{ZnO}$ is known to show two main emission bands under photoexcitation. The first band in the ultraviolet range (around $3.25 \mathrm{eV}$ ) is generally attributed to recombination of free or bound excitons close to the bandgap. ${ }^{[65]}$ The second and much broader emission band mainly covers the green part of the visible spectrum $(2.3-2.6 \mathrm{eV})$ and is therefore usually called "green band emission". The origin of this visible PL signal has been related to various types of defects, such as singly ionized oxygen vacancies, ${ }^{[66]}$ antisite oxygen, ${ }^{[67]}$ or donor-acceptor recombination. ${ }^{[68,69]}$

In this context it is an interesting question whether the relative and the absolute intensities of both near-bandgap and defect luminescence can be controlled by the external parameters of the synthesis. Therefore, we measured the PL spectra of four different samples (OZ300, OZ500, OZ750, and OZ900) which are shown in Figure 9. It can be seen that the total PL intensity of the near-bandgap transition $I_{\mathrm{B}}$ strongly increases (by more than a factor of 25) with increasing sintering temperature $T$. At the same time the total amount of defect luminescence $I_{\mathrm{D}}$ decreases. As a result of both, the ratio of defects to near-bandgap luminescence $I_{\mathrm{D}} / I_{\mathrm{B}}$ decreases strongly with $T$ (inset of Figure 9). We believe that the observed behavior of the PL properties is directly related to the sintering process of the nanoparti- 


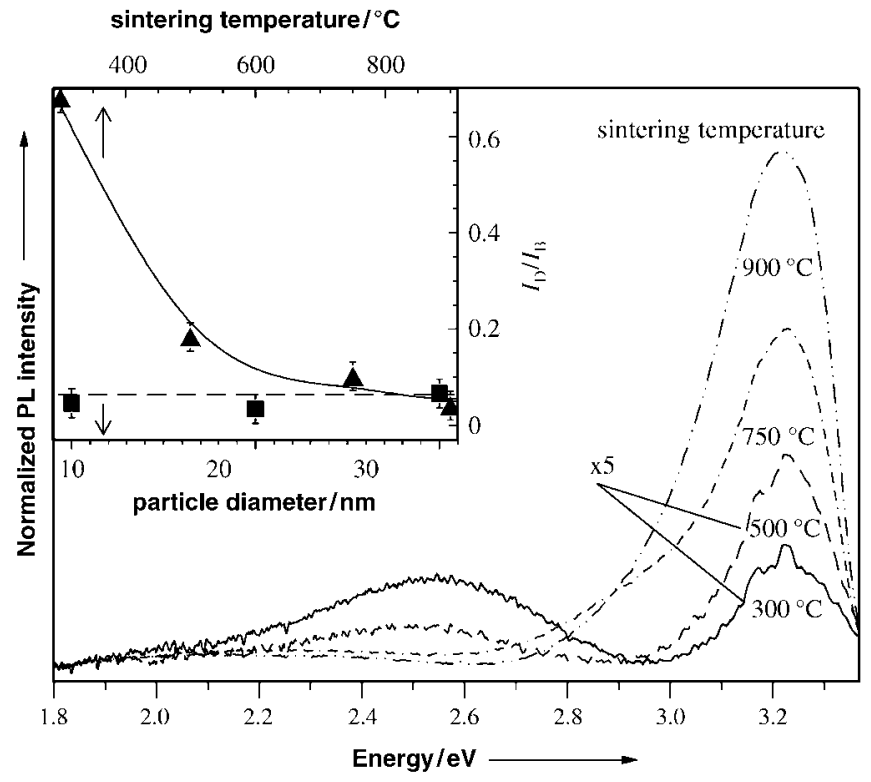

Figure 9. Photoluminescence spectra of polydisperse $\mathrm{ZnO}$ nanoparticles synthesized by CVS at varying sintering temperatures. Inset: ratio of defect to band-to-band intensities over sintering temperature and particle size for monodisperse particles sintered at $900^{\circ} \mathrm{C}$.

cles and can be controlled thereby. At a temperature of $900^{\circ} \mathrm{C}$ highly crystalline $\mathrm{ZnO}$ nanoparticles were obtained (see Figure 5). The PL spectra show virtually no defect luminescence and a strong transition close to the bandgap. On the other hand, for temperatures below $500{ }^{\circ} \mathrm{C}$ the sintering process is strongly inhibited and no annealing of defects can occur. Thus, agglomerates of particles with a high defect density are being probed instead of single nanocrystals. These defects can cause both green luminescence and nonradiative recombination that reduces the overall PL intensity.

It is important to mention that the particle diameter varied with sintering temperature $T$. As can be seen in Table 1 , the average diameter of the primary particles increases from $8 \mathrm{~nm}$ for $T=300^{\circ} \mathrm{C}$ to $29 \mathrm{~nm}$ for $T=900^{\circ} \mathrm{C}$. An increase of the particle diameter leads to a lower surface-to-volume ratio and might therefore contribute to the observed changes in the PL signal with $T$. To ensure that this is not the dominant effect in our samples, we measured size-classified nanoparticles synthesized at $T=900^{\circ} \mathrm{C}$ with diameters of 10,20 , and $30 \mathrm{~nm}$. As can be seen in the inset of Figure 9, no significant variation of $I_{\mathrm{D}} / I_{\mathrm{B}}$ with particle size was found, which clearly demonstrates that the sintering temperature rather than the particle size is mainly responsible for the present observations.

\section{Conclusions}

The goal of the current work was to develop a method of preparing isolated $\mathrm{ZnO}$ nanoparticles with adjustable size and high purity. It was shown that the heterocubane cluster
$\left[\mathrm{CH}_{3} \mathrm{ZnOCH}\left(\mathrm{CH}_{3}\right)_{2}\right]_{4}$ is a suitable precursor to obtain highpurity $\mathrm{ZnO}$ under oxidizing conditions. However, we learned that it was very difficult to control the size of the nanoparticles by solid-state synthesis, and that instead of isolated particles, agglomerates were always obtained. We therefore concentrated on the gas-phase synthesis (CVS) of $\mathrm{ZnO}$. The gas-phase mechanism of decomposition of the heterocubane precursor was investigated in detail, and it was shown that in the absence of $\mathrm{O}_{2}$ elemental zinc is produced due to the elimination of acetone and other organic groups from the cluster framework. This scenario was further supported by MS/MS experiments, which clearly showed that the heterocubane tends to eliminate acetone. In addition to the morphological control over $\mathrm{ZnO}$, it was possible to obtain $\mathrm{ZnO}$ particles free of any impurities. The samples obtained from the solid-state decomposition were applied as a reference system, in which it was not possible to obtain pure and defect-free materials.

However, it was seen that structural defects can also influence the physical properties of $\mathrm{ZnO}$. As the main factor we identified the presence of oxygen defects in the $\mathrm{ZnO}$ lattice. In combination with photoluminescence spectra the factors influencing such oxygen defects could be analyzed. It was shown that it is also possible to obtain defect-free $\mathrm{ZnO}$ materials by CVS.

\section{Experimental Section}

The volatile single-source precursor used in this method was synthesized by performing all reactions under inert conditions with the Schlenck technique. A Schlenck flask containing toluene $(50 \mathrm{~mL})$ and a $2 \mathrm{M} \mathrm{Zn}\left(\mathrm{CH}_{3}\right)_{2}$ solution in toluene $(10 \mathrm{~mL})$ was cooled to $-78^{\circ} \mathrm{C}$. Dry isopropanol $(1.2 \mathrm{~g})$ was slowly added and, after warming to room temperature, a clear solution was obtained. The solvent was removed in vacuo to give pure $\left[\mathrm{CH}_{3}\right.$ $\left.\mathrm{ZnOCH}\left(\mathrm{CH}_{3}\right)_{2}\right]_{4} \quad(2.3 \mathrm{~g}$; $90 \%) .{ }^{1} \mathrm{H} \mathrm{NMR}\left(250 \mathrm{MHz}\right.$, [ $\left.\mathrm{D}_{6}\right]$ benzene, $25^{\circ} \mathrm{C}$, TMS $): \delta=0\left(\mathrm{~s}, 3 \mathrm{H}, \mathrm{ZnCH}_{3}\right), 1.45\left(\mathrm{~d}, 6 \mathrm{H}, \mathrm{C}\left(\mathrm{CH}_{3}\right)_{2}\right)$, $4.21 \mathrm{ppm}$ (sept, $1 \mathrm{H}, \mathrm{CH}$ ).

The gas-phase decomposition of the precursor was performed at normal pressure of pure nitrogen and 20\% (by volume) oxygen, respectively, at different temperatures. The experimental setup used for CVS is depicted in Figure 2. The precursor was evaporated in a tube furnace at $40-100^{\circ} \mathrm{C}$ and then carried to another tube furnace by nitrogen at a flow rate of $1.5 \mathrm{~L} \mathrm{~min}^{-1}$. For oxidative conditions, $\mathrm{N}_{2}\left(1.2 \mathrm{Lmin}^{-1}\right)$ was passed over the precursor and $\mathrm{O}_{2}\left(0.3 \mathrm{~L} \mathrm{~min}^{-1}\right)$ was applied. Decomposition of the precursor, particle formation and subsequent growth, and sintering of the formed particles took place in a second furnace at elevated temperatures. Details of the CVS conditions are given in Table 1. The particles formed after decomposition remained as an aerosol in the gas phase, and were then passed through an a-source $\left({ }^{241} \mathrm{Am}\right)$ to charge the particles. The polydisperse charged particles were then either deposited directly or passed through a differential mobility analyzer (NANO-DMA, TSI, Minneapolis, USA) for size classification and then deposited with $\approx 100 \%$ efficiency on a suitable substrate (TEM grid or Si 
wafer) using an electrostatic precipitator. ${ }^{[70]} \mathrm{A}$ condensation nucleus counter (CNC, TSI, Model 3022, Minneapolis, USA) was used to monitor the aerosol number concentration. The polydisperse aerosol produced was also examined with the differentialmobility particle sizing technique (DMPS, TSI, Model 3081) for particle size distribution with respect to time, precursor evaporation temperature, and precursor decomposition temperature.

PXRD analyses of all powder samples and deposited particles were performed on a Bruker AXS D8 Advance instrument using $\mathrm{Cu}_{\mathrm{Ka}}$ radiation $(\lambda=1.5418 \AA)$ and a position-sensitive detector (PSD). Thermogravimetric analyses (differential thermal analysis (DTA)-TGA) of the precursor were carried out with a thermogravimetric setup from Rubotherm in the range 25 to $900^{\circ} \mathrm{C}$ in argon and oxygen. A linear rate of heating of $5 \mathrm{~K} \mathrm{~min}^{-1}$ was maintained during all the measurements. Conventional transmission electron microscopy (TEM) was performed on a Philips CM12 microscope ( $\mathrm{LaB}_{6}$ filament, $120 \mathrm{kV}$, twin lens) equipped with an energy-dispersive $\mathrm{X}$-ray spectrometer (EDX, type Oxford Link). The powder samples obtained by solid-state decomposition were suspended in cyclohexane using an ultrasonic bath for $5 \mathrm{~min}$ and then left to dry on a carbon-coated TEM grid. FIIR spectra were recorded with a Bruker Vector 22 spectrometer ( $\mathrm{KBr}$ pellets). UV/Vis spectra were recorded using a Perkin-Elmer Lambda 20 spectrometer equipped with a reflecting sphere, Labsphere RSA-PE-20. Solid-state NMR spectra were recorded using a Bruker DRX 400 spectrometer.

The optical properties of $\mathrm{ZnO}$ nanoparticles synthesized by CVS were studied by room-temperature photoluminescence spectroscopy. The samples were excited with the 351-nm UV line of an argon ion laser. The emission was dispersed by a $300-\mathrm{mm}$ monochromator and recorded by a thermoelectrically cooled charge-coupled device (CCD) camera. To avoid saturation of possible defect luminescence, low excitation densities were used $\left(P_{\text {Laser }}=2.8 \mathrm{~W} \mathrm{~cm}^{-2}\right)$.

The gas-phase experiments were performed with a modified VG ZAB/HF/AMD 604 four-sector mass spectrometer of BEBE configuration ( $B$ stands for magnetic and $E$ for electric sector), which has been described elsewhere. ${ }^{[71]}$ In brief, cations were generated by electron ionization (EI) of $\left[\mathrm{CH}_{3} \mathrm{ZnOCH}\left(\mathrm{CH}_{3}\right)_{2}\right]_{4}$ introduced via a solid probe. After acceleration to a kinetic energy of $8 \mathrm{keV}$, the ions of interest were mass-selected and subjected to metastable ion (MI) and collisional activation (CA) studies. MI spectra of $B(1) / E(1)$ mass-selected ions were recorded by detection of the charged fragments formed unimolecularly in the fieldfree region between $\mathrm{E}(1)$ and $\mathrm{B}(2)$ by scanning the latter sector. CA spectra were recorded in the same manner using helium (80\% transmission) as a stationary collision gas. All spectra reported refer to mass selection of the pure ${ }^{64} \mathrm{Zn}$ isotopes; losses of neutral zinc compounds were confirmed by the spectra of the ions containing one ${ }^{66} \mathrm{Zn}$ atom. The vapor pressure of the heterocubane was measured by Dr. P. Schmidt (TU Dresden, Germany) using a membrane-zero manometer as described elsewhere. ${ }^{[34,35]}$

\section{Acknowledgment}

We thank Dr. P. Schmidt (TU Dresden, Germany) for the determination of the vapor pressure of the heterocubane. Dr. W. Schmidt (Max-Planck Institute for Coal Research, Germany) is gratefully acknowledged for the TGA-MS measurements. We thank Deutsche Forschungsgemeinschaft (SPP 1119, CVS of nanocrystalline metal oxide and silicate films by pyrolysis of molecular metal alkoxides and metal siloxides) for financial support. We also thank H. Zähres (University Duisburg-Essen, Germany) for the TEM measurements.

[1] Acc. Chem. Res. 1999, 32, Special Issue on Nanoscale Materials.

[2] Chem. Mater. 1996, 8, Special Issue on Nanostructured Materials.

[3] Y. N. Xia, P. D. Yang, Y. G. Sun, Y. Y. Wu, B. Mayers, B. Gates, Y. D. Yin, F. Kim, Y. Q. Yan, Adv. Mater. 2003, 15, 353.

[4] L. M. Liz-Marzán, D. J. Norris, MRS Bull. 2001, 26, 981.

[5] P. Moriarty, Rep. Prog. Phys. 2001, 64, 297.

[6] H. Gleiter, Acta Mater. 2000, 48, 1.

[7] D. C. Look, B. Claftin, Phys. Status Solidi B 2004, 241, 624.

[8] B. K. Meyer, H. Alves, D. M. Hofmann, W. Kriegseis, D. Forster, F. Bertram, J. Christen, A. Hoffmann, M. Strassburg, M. Dworzak, U. Haboeck, A. V. Rodina, Phys. Status Solidi B 2004, 241, 231.

[9] D. C. Look, D. C. Reynolds, C. W. Litton, R. L. Jones, D. B. Eason, G. Cantwell, Appl. Phys. Lett. 2002, 81, 1830.

[10] M. A. Martinez, J. Herrero, M. T. Gutierrez, Sol. Energy Mater. Sol. Cells 1997, 45, 75.

[11] N. A. Anderson, X. Ai, T. Q. Lian, J. Phys. Chem. B 2003, 107, 14414.

[12] K. Keis, J. Lindgren, S. E. Lindquist, A. Hagfeldt, Langmuir 2000, $16,4688$.

[13] Y. Darici, P. H. Holloway, J. Sebastian, T. Trottier, S. Jones, J. Rodriquez, J. Vac. Sci. Technol. A 1999, 17, 692.

[14] E. Monroy, F. Omnes, F. Calle, Semicond. Sci. Technol. 2003, 18, R33.

[15] H. M. Lin, S. J. Tzeng, P. J. Hsiau, W. L. Tsai, Nanostruct. Mater. 1998, 10, 465.

[16] D. R. Clarke, J. Am. Ceram. Soc. 1999, 82, 485.

[17] H. Wilmer, M. Kurtz, K. V. Klementiev, O. P. Tkachenko, W. Grünert, O. Hinrichsen, A. Birkner, S. Rabe, K. Merz, M. Driess, C. Wöll, M. Muhler, Phys. Chem. Chem. Phys. 2003, 5, 4736.

[18] S. J. Pearton, D. P. Norton, K. Ip, Y. W. Heo, T. Steiner, J. Vac. Sci. Technol. 2004, 22, 932.

[19] Z. L. Wang, J. Phys. Condens. Matter 2004, 16, R829.

[20] R. Viswanatha, S. Sapra, B. Satpati, P. V. Satyam, B. N. Dev, D. D. Sarma, J. Mater. Chem. 2004, 14, 661.

[21] G. Rodriguez-Gattorno, P. Santiago-Jacinto, L. Rendon-Vazquez, J. Nemeth, I. Dekany, D. Diaz, J. Phys. Chem. B 2003, 107, 12597.

[22] Z. S. Hu, G. Oskam, P. C. Searson, J. Colloid Interface Sci. 2003, 263, 454.

[23] M. Shim, P. Guyot-Sionnest, J. Am. Chem. Soc. 2001, 123, 11651.

[24] E. A. Meulenkamp, J. Phys. Chem. B 1998, 102, 5566.

[25] V. Noack, A. Eychmuller, Chem. Mater. 2002, 14, 1411.

[26] F. E. Kruis, H. Fissan, A. Peled, J. Aerosol Sci. 1998, 29, 511.

[27] T. Tani, L. Madler, S. E. Pratsinis, J. Nanopart. Res. 2002, 4, 337.

[28] R. Wu, C. S. Xie, H. Xia, J. H. Hu, A. H. Wang, J. Cryst. Growth 2000, 217, 274.

[29] A. Roy, S. Polarz, S. Rabe, B. Rellinghaus, H. Zahres, F. E. Kruis, M. Driess, Chem. Eur. J. 2004, 10, 1565. 
[30] S. Seifried, M. Winterer, H. Hahn, Chem. Vap. Deposition 2000, 6, 239.

[31] M. Driess, K. Merz, R. Schoenen, S. Rabe, F. E. Kruis, A. Roy, A. Birkner, CR Chim. 2003, 6, 273.

[32] H. Kleinwechter, C. Janzen, J. Knipping, H. Wiggers, P. Roth, J. Mater. Sci. 2002, 37, 4349.

[33] C. G. Kim, K. W. Sung, T. M. Chung, D.Y. Jung, Y. Kim, Chem. Commun. 2003, 2068.

[34] P. Schmidt, H. Oppermann, Z. Naturforsch. B 2000, 55, 603.

[35] P. Schmidt, H. Oppermann, N. Soger, M. Binnewies, A. N. Rykov, K. O. Znamenkov, A. N. Kuznetsov, B. A. Popovkin, Z. Anorg. Allg. Chem. 2000, 626, 2515.

[36] E. Lifshin, Characterization of Materials, Wiley-VCH, Weinheim, 1999.

[37] X. S. Peng, L. D. Zhang, G. W. Meng, X. Y. Yuan, Y. Lin, Y. T. Tian, J. Phys. D 2003, 36, L35.

[38] Y. Xiong, S. W. Lyons, T. T. Kodas, S. E. Pratsinis, J. Am. Ceram. Soc. 1995, 78, 2490.

[39] S. W. Lyons, Y. Xiong, T. T. Ward, T. T. Kodas, S. E. Pratsinis, J. Mater. Res. 1992, 7, 3333.

[40] J. Auld, D. J. Houlton, A. C. Jones, S. A. Rushworth, M. A. Malik, P. Obrien, G. W. Critchlow, J. Mater. Chem. 1994, 4, 1249.

[41] C. J. Cassady, B. S. Freiser, J. Am. Chem. Soc. 1985, 107, 1566.

[42] C. J. Cassady, B. S. Freiser, J. Am. Chem. Soc. 1985, 107, 1573.

[43] C. J. Cassady, B. S. Freiser, S. W. McElvany, J. Allison, J. Am. Chem. Soc. 1984, 106, 6125.

[44] D. Schröder, H. Schwarz, Angew. Chem. 1990, 102, 925; Angew. Chem. Int. Ed. Engl. 1990, 29, 910.

[45] A. Fiedler, D. Schroder, H. Schwarz, B. L. Tjelta, P. B. Armentrout, J. Am. Chem. Soc. 1996, 118, 5047.

[46] T. Seto, M. Shimada, K. Okuyama, Aerosol Sci. Technol. 1995, 23, 183.

[47] Y. Xing, D. E. Rosner, J. Nanopart. Res. 1999, 1, 277.

[48] Y. Xing, U. O. Koylu, D. E. Rosner, Combust. Flame 1996, 107, 85 .

[49] K. Nakaso, T. Fujimoto, T. Seto, M. Shimada, K. Okuyama, M. M. Lunden, Aerosol Sci. Technol. 2001, 35, 929.

[50] S. Tsantilis, H. Briesen, S. E. Pratsinis, Aerosol Sci. Technol. 2001, 34, 237.

[51] R. M. German, Sintering Theory and Practice, Wiley, New York, 1996.
[52] W. S. Coblenz, J. M. Dynys, R. M. Cannon, R. L. Coble, Mater. Sci. Res. 1980, 13, 141.

[53] F. E. Kruis, K. A. Kusters, S. E. Pratsinis, B. Scarlett, Aerosol Sci. Technol. 1993, 19, 514.

[54] A. P. Hynes, R. H. Doremus, R. W. Siegel, J. Am. Ceram. Soc. 2002, 85, 1979.

[55] A. Kobata, K. Kausakabe, S. Morooka, AlChE J. 1991, 37, 347.

[56] M. Shimada, T. Seto, K. Okuyama, J. Chem. Eng. Jpn. 1994, 27, 795.

[57] K. Nakaso, M. Shimada, K. Okuyama, K. Deppert, J. Aerosol Sci. 2002, 33, 1061.

[58] M. A. S. N. Nogueira, W. B. Ferraz, A. C. S. Sabioni, Mater. Res. 2003, 6, 167.

[59] J.-G. Li, J. Mater. Sci. Lett. 1994, 13, 400

[60] J. Z. Jiang, J. S. Olsen, L. Gerward, D. Frost, D. Rubie, J. Peyronneau, Europhys. Lett. 2000, 50, 48.

[61] A. C. S. Sabioni, M. J. F. Ramosm, W. B. Ferraz, Mater. Res. 2003, $6,173$.

[62] S. K. Friedlander, M. K. Wu, Phys. Rev. B 1994, 49, 3622.

[63] G. W. Tomlins, J. L. Routbort, T. O. Mason, J. Appl. Phys. 2000, $87,117$.

[64] A. Wood, M. Giersig, M. Hilgendorff, A. Vilas-Campos, L. M. LizMarzan, P. Mulvaney, Aust. J. Chem. 2003, 56, 1051.

[65] D. M. Bagnall, Y. F. Chen, Z. Zhu, T. Yao, M. Y. Shen, T. Goto, Appl. Phys. Lett. 1998, 73, 1038.

[66] K. Vanheusden, W. L. Warren, C. H. Seager, D. R. Tallant, J. A. Voigt, B. E. Gnade, J. Appl. Phys. 1996, 79, 7983.

[67] B. X. Lin, Z. X. Fu, Y. B. Jia, Appl. Phys. Lett. 2001, 79, 943.

[68] D. C. Reynolds, D. C. Look, B. Jogai, J. Appl. Phys. 2001, 89, 6189.

[69] S. A. Studenikin, M. Cocivera, J. Appl. Phys. 2002, 91, 5060.

[70] F. E. Kruis, K. Nielsch, H. Fissan, B. Rellinghaus, E. F. Wassermann, Appl. Phys. Lett. 1998, 73, 547.

[71] C. A. Schalley, M. Dieterle, D. Schroder, H. Schwarz, E. Uggerud, Int. J. Mass Spectrom. Ion Processes 1997, 163, 101.

Received: September 28, 2004 Revised: January 26, 2005 